\section{Cancer-Like Eosinophilic Gastritis}

Eosinophilic gastroenteritis (EG) is an uncommon disease, characterized by infiltration of eosinophilic leukocytes into the gastrointestinal tract, which was first described by Kaijser in 1937 (1). Up to the present, about 200 cases of EG have been reported, and diagnostic criteria such as the presence of gastrointestinal symptoms, biopsies showing eosinophilic infiltration of one or more areas of the gastrointestinal tract and an absence of any parasitic or extraintestinal disease, have been established (2). We present here a case of EG which imitated stomach cancer, and recurred after surgical therapy. A 40-year-old man suffering from epigastralgia, nausea, and weakness was initially diagnosed on endoscopic examination as having stomach cancer, due to a large ulcerovegetative tumor mass. Pathology consistently failed to prove malignancy. A Billroth I resection was performed for the giant, intractable lesion, without any complications. The histopathological diagnosis was EG. At a three-month follow-up, endoscopy revealed erythematous changes and edema of the mucosa of the remaining stomach. At the six-month follow-up, a sessile tumor mass with a hard consistency, $3 \mathrm{~cm}$ in diameter and with a fragile mucosa was encountered (Figure 1). Serial biopsies were all consistent with EG, and the patient was given methylprednisolone, $40 \mathrm{mg}$ per day orally, for two months. A suture thread that became apparent at the base of the lesion after one month of steroid therapy was successfully removed endoscopically (Figure 2). Steroid therapy led to excellent resolution after about two and a half months, and the patient was recurrence-free at the two-year follow-up. In conclusion, EG should be seriously considered in patients with an endoscopic diagnosis of gastric carcinoma in whom the histopathology consistently fails to confirm malignancy. The evolution of gastric EG seems to follow a sequence of mucosal hyperemia, protrusion, and ulceration. Steroid therapy may offer dramatic improvement, and should be the first-line therapeutic approach.

N. Örmeci, F. Bayramoğlu, Ö. Tulunay, M. A. Yerdel,

A. Önbayrak, Ö. Uzunalimoglu

Departments of Gastroenterology

Pathology and General Surgery

Ankara University Medical School

Ankara, Turkey

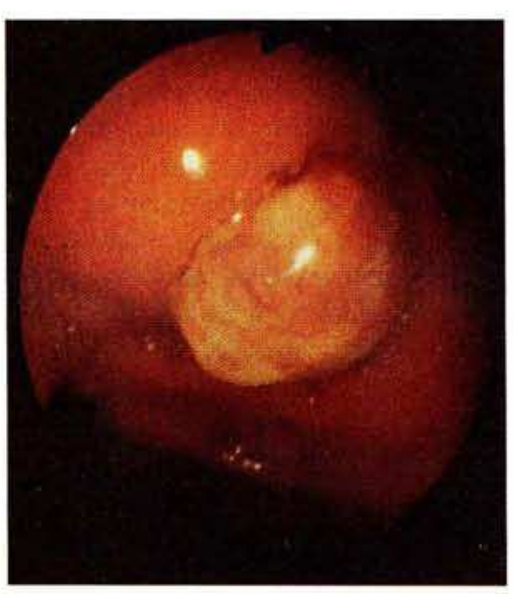

Figure 1:

Endoscopic

image showing a

sessile tumor with

eroded mucosa,

located at the

posterior wall

near the angulus.

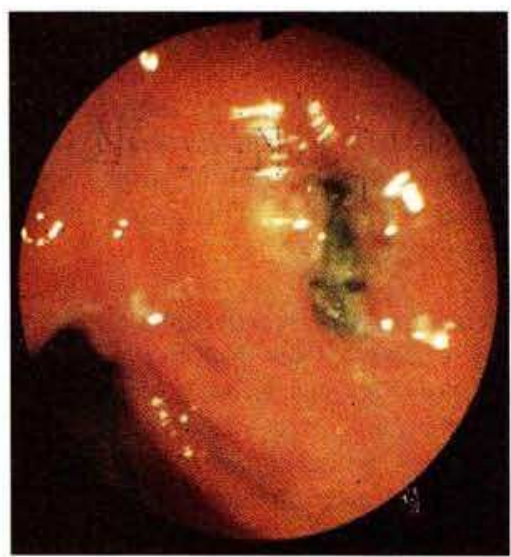

Figure 2:

Endoscopic image one month after steroid therapy. Note the presence of a silk suture thread at the base of the tumor.

\section{References}

1 Kaijser R: Zur Kenntnis der allergischen Affektionen des Verdauungskanals vom Standpunkt des Chirurgen aus. Arch. Klin. Chir. 1937; 188: 36-44.

2 Talley JN, Shorter GR, Philips FS et al.: Eosinophilic gastroenteritis: a clinicopathological study of patients with disease of the mucosa, muscle layer and subserosal tissues. Gut 1990; 31: 54-58.

Corresponding Author

N. Örmeci, M.D., Yüksel Cad. 33/3,

Yenișehir, Ankara, Turkey 